\title{
Novel Algorithm for the Differential Diagnosis of Hyponatraemia in Anuric Patients Undergoing Maintenance Haemodialysis
}

\author{
Lenka Vitova $^{\mathrm{a}}$ Monika Tothova $^{\mathrm{b}}$ Otto Schuck $^{\mathrm{c}}$ Miroslava Horackova $^{\mathrm{a}}$ \\ aDepartment of Internal Medicine, Second faculty of Medicine, Charles University in Prague and Motol University \\ Hospital, Prague, Czech Republic; ${ }^{b}$ Haemodialysis Centre, Fresenius NephroCare Motol, Prague, Czech Republic; \\ 'Second faculty of Medicine, Charles University in Prague, Prague, Czech Republic
}

\section{Keywords}

Hyponatraemia · Maintenance haemodialysis · Interdialysis interval · Pathophysiology

\begin{abstract}
Introduction: Hyponatraemia is associated with increased mortality in patients undergoing maintenance haemodialysis. In anuric patients, hyponatraemia development depends on the water-sodium ratio in retained fluid within the interdialysis interval (IDI). Objective: This study aimed to calculate the retained sodium-retained water ratio in patients on maintenance haemodialysis and make a differential diagnosis of hyponatraemia according to these data. Methods: The amount of retained water was determined as body weight gain $(\triangle B W)$ within the IDI. Sodium retention was calculated using our formula: $\mathrm{eRNa}^{+}=\Delta \mathrm{BW} \times\left(\mathrm{SNa}^{+}\right)_{\mathrm{t} 2}-$ total body water $(\mathrm{TBW})_{\mathrm{t} 1} \times\left(\left[\mathrm{SNa}^{+}\right]_{\mathrm{t} 1}-\left[\mathrm{SNa}^{+}\right]_{\mathrm{t} 2}\right)$, where TBW represents the calculated volume of the total body water and $\left(\mathrm{SNa}^{+}\right)_{\mathrm{t} 1}$ and $\left(\mathrm{SNa}^{+}\right)_{\mathrm{t} 2}$ represent the sodium concentration at the beginning and at the end of the IDI, respectively. We performed 89 measurements in 32 anuric patients on maintenance haemodialysis. Results: Hyponatraemia was detected in 13 measurements at the end of the IDI. The $\Delta \mathrm{BW}$ had no statistically
\end{abstract}

significant difference between normonatraemic and hyponatraemic patients. Hyponatraemic patients had significantly lower levels of retained sodium. The retained waterretained sodium ratio facilitated in differentiating dilution hyponatraemia, nutritional hyponatraemia, depletion hyponatraemia, and dilution hyponatraemia associated with sodium wasting or malnutrition. Conclusion: The composition of retained fluid during the IDI may be hypotonic, hypertonic, or isotonic in relation to the extracellular fluid. Most of the hyponatraemic patients had hypotonic fluid retained during the IDI because of dilution as well as gastrointestinal sodium loss and/or malnutrition.

(C) 2021 The Author(s).

Published by S. Karger AG, Basel

\section{Introduction}

Hyponatraemia is a serious complication in patients on maintenance haemodialysis, with an incidence rate of approximately 6-29\% [1]. Generally, it is a result of excessive oral water intake within the interdialysis interval (IDI), causing sodium dilution in the extracellular fluid. In fact, it is associated with increased mortality [2-4]. According to the MONDO study, hyponatraemia is associ-

karger@karger.com www.karger.com/kbr

Karger $\stackrel{\text { ' }}{5}$

BOPEN ACCESS
(C) 2021 The Author(s)

Published by S. Karger AG, Basel

This is an Open Access article licensed under the Creative Commons Attribution-NonCommercial-4.0 International License (CC BY-NC) (http://www.karger.com/Services/OpenAccessLicense), applicable to the online version of the article only. Usage and distribution for commercial purposes requires written permission. 
ated with malnutrition and inflammation and can also develop in patients without excessive interdialysis weight gain [5]. In anuric patients, predialysis serum sodium concentration $\left(\mathrm{SNa}^{+}\right)$depends on water and sodium oral intakes and extrarenal water and sodium losses during the IDI, and it is largely determined by the final body water-and-sodium balance (water/sodium ratio).

The differential diagnosis of hyponatraemia in patients on maintenance haemodialysis is, amongst other criteria, based on the estimated dietary sodium intake, which can be calculated from the dietary salt intake. Unfortunately, nutritional counselling is difficult to implement daily. Inaccuracy of patients' food reports and variable sodium content in foods can make sodium intake assessment challenging [6].

However, estimating the retained water and sodium during the IDI is crucial for the differential diagnosis and adequate treatment of hyponatraemia in anuric patients. Hence, our study aimed to develop an algorithm to estimate the amount of retained sodium during the IDI according to sodium concentrations and hydration status.

\section{Methods}

\section{Study Population}

We included 32 anuric (diuresis $<100 \mathrm{~mL} / 24 \mathrm{~h}$ ) patients, with a mean age of 69 (42-93) years, in a regular haemodialysis programme at the Fresenius Medical Care Haemodialysis Centre in Motol, Prague. These patients had been on maintenance haemodialysis for a mean of $7.7(0.6-27.7)$ years. Furthermore, 14 of them were male.

The individualized treatment of all study patients conformed to the anaemia, bone metabolism, hypertension, and sodium and water dietary intake guidelines [7-9]. The causes of end-stage kidney disease were vascular nephropathy (37.4\%), diabetic kidney disease $(18.8 \%)$, tubulointerstitial nephritis (15.6\%), polycystic kidney disease (12.5\%), glomerulonephritis (6.3\%), and other nephropathies (9.4\% including unknown causes). All study patients were treated with haemodiafiltration with postdilution or mixdilution on the FMC 5008 or FMC 5008 CorDiax dialysis machine, with the FX 600 CorDiax HDF dialysator.

Adequate haemodialysis dose was achieved by individualised intradialytic conditions. A patent vascular access was ensured in all patients to allow an extracorporeal blood flow $\left(\mathrm{Q}_{\mathrm{b}}\right)$ of $400-500$ $\mathrm{mL} / \mathrm{min}$. Dialysate flow $\left(\mathrm{Q}_{\mathrm{d}}\right)$ was regulated by the incorporated AutoFlow function at AF $1.0-1.2\left(\mathrm{Q}_{\mathrm{d}} / \mathrm{Q}_{\mathrm{b}}\right)$. All patients met the high-volume haemodialfiltration adequacy criteria [10].

The dialysate composition $\left(\mathrm{Na}^{+}, \mathrm{K}^{+}\right.$and $\mathrm{HCO}_{3-}$ concentrations) was adjusted monthly according to the laboratory results and clinical status of each study patient. The dialysate temperature was maintained within $35.5-36.5^{\circ} \mathrm{C}$. A sodium control software controlled the dialysate sodium concentrations according to the repeated intradialytic measurements of sodium concentrations in all patients [11].
Moreover, dry weight was evaluated once monthly by the bioelectrical impedance analysis (FMC Body Composition Monitor device) and was adjusted in concordance with the clinical hydration status and blood pressure control [12]. We also considered the maximum tolerable rates and volumes of ultrafiltration. In cases of discrepancy between the bioelectrical impedance analysis and the clinical hydration status, the inferior vena cava diameter and extravascular lung water were measured via ultrasonography $[13,14]$.

\section{Assessment of Water and Sodium Retention}

The amount of retained water was determined as body weight gain $(\triangle \mathrm{BW})$ within the IDI. We worked up the following approach to assess sodium retention. We considered sodium distribution volume as the total body water (TBW) volume that could reflect the fluid and sodium shifts between the extracellular and intracellular compartments. TBW was calculated from the body weight (BW), specifically $50 \%$ of BW in women and $60 \%$ in men [15]. The amount of total body sodium (TBS) at the beginning of IDI $\left(\mathrm{TBS}_{\mathrm{t} 1}\right)$ was calculated by multiplying the TBW at the beginning of IDI $(\mathrm{TBW})_{\mathrm{t} 1}$ and the serum sodium concentration at that time $\left(\mathrm{SNa}^{+}\right)_{\mathrm{t} 1}$, that is, $\mathrm{TBS}_{\mathrm{t} 1}=\mathrm{TBW}_{\mathrm{t} 1} \times\left(\mathrm{SNa}^{+}\right)_{\mathrm{t} 1}$.

The TBW at the end of IDI $\left(\mathrm{TBW}_{\mathrm{t} 2}\right)$ was calculated by adding the $\mathrm{TBW}_{\mathrm{t} 1}$ and the body weight change $(\Delta \mathrm{BW})$, that is, $\mathrm{TBW}_{\mathrm{t} 2}=$ $\mathrm{TBW}_{\mathrm{t} 1}+\Delta \mathrm{BW}$. The TBS at the end of IDI $\left(\mathrm{TBS}_{\mathrm{t} 2}\right)$ was calculated by multiplying the $\mathrm{TBW}_{\mathrm{t} 2}$ and the serum sodium concentration at the end of IDI $\left(\mathrm{SNa}^{+}\right)_{\mathrm{t} 2}$, that is, $\mathrm{TBS}_{\mathrm{t} 2}=\left(\mathrm{TBW}_{\mathrm{t} 1}+\Delta \mathrm{BW}\right) \times\left(\mathrm{SNa}^{+}\right)_{\mathrm{t} 2}$.

Changes in the TBS within IDI corresponded with the sodium retention within IDI $\left(\mathrm{RNa}^{+}\right)$. To calculate the estimated sodium retention within IDI $\left(\mathrm{eRNa}^{+}\right)$, we derived the following formula by using the abovementioned values:

$$
e R N a^{+}=\Delta B W \times\left(S N a^{+}\right)_{t 2}-T B W_{t 1} \times\left[\left(S N a^{+}\right)_{t 1}-\left(S N a^{+}\right)_{t 2}\right]
$$

In patients with no shifts in the sodium concentration within the IDI, the $\left[\left(\mathrm{SNa}^{+}\right)_{\mathrm{t} 1}-\left(\mathrm{SNa}^{+}\right)_{\mathrm{t} 2}\right]$ part of the equation approximated the zero value. In such cases, $\mathrm{eRNa}^{+}=\Delta \mathrm{BW} \times\left(\mathrm{SNa}^{+}\right)_{\mathrm{t} 2}$ applied. In patients with shifts in the $\mathrm{SNa}^{+}$, the full formula must be used. The $\mathrm{eNa}^{+}$value represents the dietary sodium intake in anuric patients whose extrarenal sodium losses have been excluded.

We performed 89 sodium and water interdialytic assessments $(\mathrm{t} 1+\mathrm{t} 2)$ within 14 months between October 2015 and December 2016. We measured the shifts in sodium and water parameters during 3 IDIs in 25 patients (i.e., $75 \mathrm{t} 1+\mathrm{t} 2$ measurements in total) and during 2 IDIs in 7 patients (i.e., $14 \mathrm{t} 1+\mathrm{t} 2$ measurements in total). The fixed time frame of IDI was $67 \mathrm{~h}$.

The $\mathrm{SNa}^{+}$values at the beginning of IDI $\left[\left(\mathrm{SNa}^{+}\right)_{\mathrm{t} 1}\right]$ and at the end of IDI $\left[\left(\mathrm{SNa}^{+}\right)_{\mathrm{t} 2}\right]$ were obtained from the dialysis vascular access $60 \mathrm{~min}$ after finishing the dialysis, that is, in a postdialysis equilibrium state, and immediately before initiating the next dialysis procedure, respectively. The $\mathrm{SNa}^{+}$values were determined electrochemically by ion selective electrodes through the dilution method on the Modular Analyser (Roche Diagnostics).

Patient BW Was Measured on the Soehnle 7724.01.001 Scale

Statistical data were analysed using the Microsoft Excel 2010 programme for basic arithmetic calculations, the StatSoft Statistica 13.2 programme for median and interquartile range calculation and the Mann-Whitney $U$ Test for $p$ value calculation $(p<0.05$ was considered statistically significant). The study obtained informed consent from all study participants and was approved by the Fresenius Medical Care - DS, s.r.o. ethical commission. 
Table 1. Statistical comparison of parameters - group 1 with normonatraemia versus group 2 with hyponatraemia at the end of the IDI

\begin{tabular}{lllllll}
\hline Group & $\left(\mathrm{S}_{\mathrm{Na}+}\right)_{\mathrm{t} 1}, \mathrm{mmol} / \mathrm{L}$ & $\left(\mathrm{S}_{\mathrm{Na}+}\right)_{\mathrm{t} 2}, \mathrm{mmol} / \mathrm{L}$ & $\mathrm{BW}_{\mathrm{t} 1}, \mathrm{~kg}$ & $\mathrm{BW}_{\mathrm{t} 2}, \mathrm{~kg}$ & $\Delta \mathrm{BW}, \mathrm{kg} / \mathrm{t} 1-\mathrm{t} 2$ & $\mathrm{eRNa}{ }^{+}, \mathrm{mmol} / \mathrm{t} 1-\mathrm{t} 2$ \\
\hline 1 median $(\mathrm{IQR})$ & $137.5(3.0)$ & $139.5(3.0)$ & $76.3(17.6)$ & $79.4(17.2)$ & $2.5(1.6)$ & $453.6(289.9)$ \\
2 median $(\mathrm{IQR})$ & $135.0(2.0)$ & $133.5(6.0)$ & $64.9(27.0)$ & $65.7(27.9)$ & $2.2(1.7)$ & $144.3(255.9)$ \\
\hline$p$ value & 0.0175 & $<0.0001$ & 0.0157 & 0.0154 & 0.5458 & $<0.0001$ \\
\hline
\end{tabular}

$\left(\mathrm{S}_{\mathrm{Na}+}\right)_{\mathrm{t} 1} /\left(\mathrm{S}_{\mathrm{Na}+}\right)_{\mathrm{t} 2}$, serum sodium concentration at the beginning/at the end of IDI; IQR, interquartile range; $\mathrm{BW}_{\mathrm{t} 1} / \mathrm{BW}_{\mathrm{t} 2}$, body weight at the beginning/at the end of IDI; $\triangle \mathrm{BW}$, body weight gain during IDI; eRNa ${ }^{+}$, estimated sodium intake during IDI; IDI, interdialysis interval.

\section{Results}

The predialysis $\left(\mathrm{SNa}^{+}\right)_{\mathrm{t} 2}$ ranged from 116 to 147 $\mathrm{mmol} / \mathrm{L}$ in the study cohort. The results from all 89 measurements ( $\mathrm{t} 1+\mathrm{t} 2$ values) were divided into 2 groups according to the $\left(\mathrm{SNa}^{+}\right)_{\mathrm{t} 2}$ levels.

1. Group $1(n=76)$ includes patients with $\left(\mathrm{SNa}^{+}\right)_{\mathrm{t} 2} \geq 135$ $\mathrm{mmol} / \mathrm{L}$ (shown in Table 1 ).

2. Group $2(n=13)$ includes patients with $\left(\mathrm{SNa}^{+}\right)_{\mathrm{t} 2}<135$ $\mathrm{mmol} / \mathrm{L}$ (shown in Table 1 ).

The $\left(\mathrm{SNa}^{+}\right)_{\mathrm{t} 2}$ defines the groups. Table 1 shows that the median values of $\left(\mathrm{SNa}^{+}\right)_{\mathrm{t} 2}$ significantly differ $(p<0.0001)$ between these 2 groups.

Table 1 also demonstrates that the $\left(\mathrm{SNa}^{+}\right)_{\mathrm{t} 1}$ in group 2 had a significantly $(p=0.0175)$ lower median value than that in group 1. The t1 BW was significantly lower in group 2 than in group 1 , but the $\Delta \mathrm{BW}$ did not differ significantly between such groups. Table 1 shows that the $\mathrm{eRNa}^{+}$within the IDI had a very significant difference $(p<0.0001)$ between the groups.

The relationship between the $\Delta \mathrm{BW}$ and $\mathrm{eRNa}^{+}$values (from individual measurements) is depicted in a scatter plot (shown in Fig. 1). As shown in the graph (Fig. 1), only 4 cases from group 2 were associated with the weight gain of $>2.8 \mathrm{~kg} / 67 \mathrm{~h}$.

In 9 cases in group 2 , the e $\mathrm{RNa}^{+}$values were lower than $238 \mathrm{mmol} / 67 \mathrm{~h}$, which represents the dietary sodium intake of $\leq 85 \mathrm{mmol} / 24 \mathrm{~h}$, that is, $5 \mathrm{~g}$ of $\mathrm{NaCl} / 24 \mathrm{~h}$ (excluding the extrarenal losses of sodium). In 4 hyponatraemia cases, the e $\mathrm{RNa}^{+}$values were negative and were associated with the weight gain of $\leq 2.8 \mathrm{~kg} / 67 \mathrm{~h}$ in 3 of these cases and even with a weight loss in 1 case. These 4 cases represent the depletion hyponatraemia, with the presence of extrarenal sodium losses.

Increased $\Delta \mathrm{BW}$ of $>2.8 \mathrm{~kg} / 67 \mathrm{~h}$ along with low $\mathrm{eRNa}^{+}$values of $<238 \mathrm{mmol} / 67 \mathrm{~h}$ suggested dilution hyponatraemia combined with a very low dietary so-

Novel Algorithm for Differential Diagnosis of Hyponatraemia in Anuria dium intake. Thus, hyponatraemia etiopathogenesis is complex in anuric patients on maintenance haemodialysis.

\section{Discussion}

In this study, hyponatraemia was observed in $31 \%$ of the patients (in $15 \%$ of measurements correspondingly), consistent with a previous study [1]. Excessive fluid intake in the IDI is usually the cause of hyponatraemia in these patients [16]. Pathophysiologically, hyponatraemia is determined by not only the absolute amount of retained water but also the retained water-retained sodium ratio in the IDI [17]. If the sodium concentration in the retained solution is lower than the physiological value of $\mathrm{SNa}^{+}$, hyponatraemia may develop after the mixture of the retained solution and extracellular water (ECW) and after the equilibration between the intra- and extracellular fluid.

The amount of retained water can be determined by measuring the BW difference at the beginning and end of IDI $(\triangle B W)$. Meanwhile, assessing the amount of retained sodium in IDI is more difficult [18]. Nevertheless, estimating the amount of retained sodium is fairly easier in anuric patients (without extrarenal sodium loss). In our study, we estimated sodium retention in IDI by using the formula stated in the methodology. This calculation requires readily available $\mathrm{SNa}^{+}$values before and after dialysis. Furthermore, TBW assessment is also difficult. For estimation (not accurate measurement), TBW can be derived from $\mathrm{BW}$ (TBW $=50 \% \mathrm{BW}$ in women, $60 \% \mathrm{BW}$ in men). This practice is accepted and recommended in contemporary prestigious monographs [15].

Perhaps, bioimpedance would provide a more accurate information about TBW [19]. Considering that TBW estimation was used in this study, we referred to the calculated value of retained sodium in IDI as eRNa . 


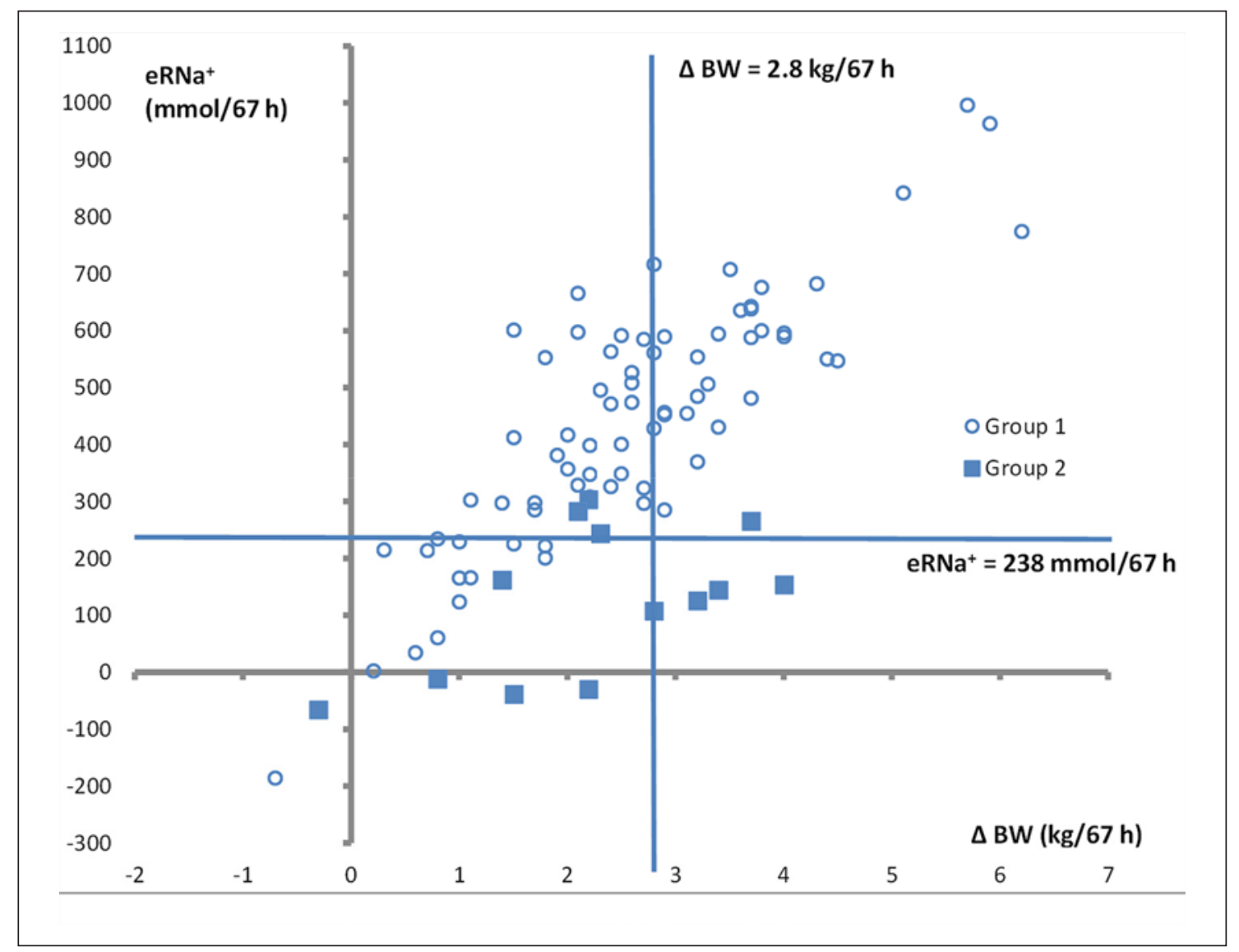

Fig. 1. Relationship between $\triangle \mathrm{BW}$ and $\mathrm{RNa}^{+}$values (from individual measurements). The graph displays a symbol for each serum sodium concentration at the end of the IDI $\left(\left[\mathrm{SNa}^{+}\right]_{\mathrm{t} 2}\right)$ and $\Delta \mathrm{BW}$ measurement with a different symbol type for each group (group 1, circle; group 2, square). The vertical line crosses the $\Delta \mathrm{BW}$ axis at the point of $2.8 \mathrm{~kg} \Delta \mathrm{BW} / 67 \mathrm{~h}$, which represents the optimal $\Delta \mathrm{BW}$ of $1 \mathrm{~kg} / 24 \mathrm{~h} \mathrm{[16].} \mathrm{The} \mathrm{horizontal} \mathrm{line} \mathrm{crosses} \mathrm{the} \mathrm{eRNa}{ }^{+}$ axis at the point of $238 \mathrm{mmol} / 67 \mathrm{~h}$, which represents the dietary sodium intake of $85 \mathrm{mmol} / 24 \mathrm{~h}$ (i.e., $14 \mathrm{~g}$ of $\mathrm{NaCl} / 67 \mathrm{~h}$ and $5 \mathrm{~g}$ of NaCl$/ 24 \mathrm{~h}$ ). IDI, interdialysis interval; $\Delta \mathrm{BW}$, body weight gain; $\mathrm{eRNa}^{+}$, estimated sodium retention.

The sodium concentration in the retained water during the IDI was calculated from the $\mathrm{RNa}^{+} / \triangle \mathrm{BW}$ ratio. The tonicity of the retained fluid during the IDI was compared with the physiological parameters in the ECW. Considering the results in Figure 1, we can predict a natraemia trend. As an example, we demonstrate 3 cases of hyponatraemia.

1. $\mathrm{eRNa}^{+}=282.5 \mathrm{mmol}, \Delta \mathrm{BW} 2.1 \mathrm{~kg}$, $\mathrm{eRNa}^{+} / \Delta \mathrm{BW}=$ $134.5 \mathrm{mmol} / \mathrm{L}, \mathrm{SNa}_{\mathrm{t} 1}=134.5 \mathrm{mmol} / \mathrm{L}, \mathrm{SNa}_{\mathrm{t} 2}=134.5$ $\mathrm{mmol} / \mathrm{L}$.

2. $\mathrm{eRNa}^{+}=303.2 \mathrm{mmol}, \Delta \mathrm{BW} 2.2 \mathrm{~kg}, \mathrm{eRNa}^{+} / \Delta \mathrm{BW}=$ $137.8 \mathrm{mmol} / \mathrm{L}, \mathrm{SNa}_{\mathrm{t} 1}=131.0 \mathrm{mmol} / \mathrm{L}, \mathrm{SNa}_{\mathrm{t} 2}=131.5$ $\mathrm{mmol} / \mathrm{L}$.

3. $\mathrm{eRNa}^{+}=262.3 \mathrm{mmol}, \Delta \mathrm{BW}=3.7 \mathrm{~kg}, \mathrm{eRNa}^{+} / \Delta \mathrm{BW}=$ $71.7 \mathrm{mmol} / \mathrm{L}, \mathrm{SNa}_{\mathrm{t} 1}=138 \mathrm{mmol} / \mathrm{L}, \mathrm{SNa}_{\mathrm{t} 2}=133.5$ $\mathrm{mmol} / \mathrm{L}$.
In the first 2 cases, $\mathrm{eRNa}^{+}$was $>238 \mathrm{mmol} / 67 \mathrm{~h}$ (corresponding to $85 \mathrm{mmol} / 24 \mathrm{~h}$ and $5 \mathrm{~g}$ of $\mathrm{NaCl} / 24 \mathrm{~h}$ ), and the $\Delta B W$ did not exceed $2.8 \mathrm{~kg} / 67 \mathrm{~h}$ (or $1 \mathrm{~kg} / 24 \mathrm{~h}$ ). In the third case, the $\mathrm{eRNa}^{+}$was $>85 \mathrm{mmol} / 24 \mathrm{~h}$, and the $\Delta \mathrm{BW}$ was $>1 \mathrm{~kg} / 24 \mathrm{~h}$. The value of $\Delta \mathrm{BW} 1 \mathrm{~kg} / 24 \mathrm{~h}$ is based on the recommendations of expert groups and is associated with the optimal value of ultrafiltration rate during haemodialysis. It should be a maximum of 13 , resp. $10 \mathrm{~mL} /$ $\mathrm{kg} \mathrm{BW/h} \mathrm{[20].} \mathrm{The} \mathrm{limit} \mathrm{of} 2.8 \mathrm{~L}$ corresponds to ultrafiltration rate of $700 \mathrm{~mL} / \mathrm{h}$ for $4 \mathrm{~h}$ of haemodialysis.

The first patient retained fluid with a sodium concentration equal to the $\mathrm{SNa}_{\mathrm{t} 1}$ during IDI, and the $\mathrm{SNa}_{\mathrm{t} 2}$ did not change. The second patient retained fluid with a sodium concentration that remains physiological in terms of ECW tonicity; during IDI, natraemia minimally increased. 
Fig. 2. Hyponatraemia classification in anuric patients according to the $\triangle \mathrm{BW}$ and $\mathrm{eRNa}^{+} . \Delta \mathrm{BW}$, body weight gain; $\mathrm{eRNa}^{+}$, estimated sodium retention.

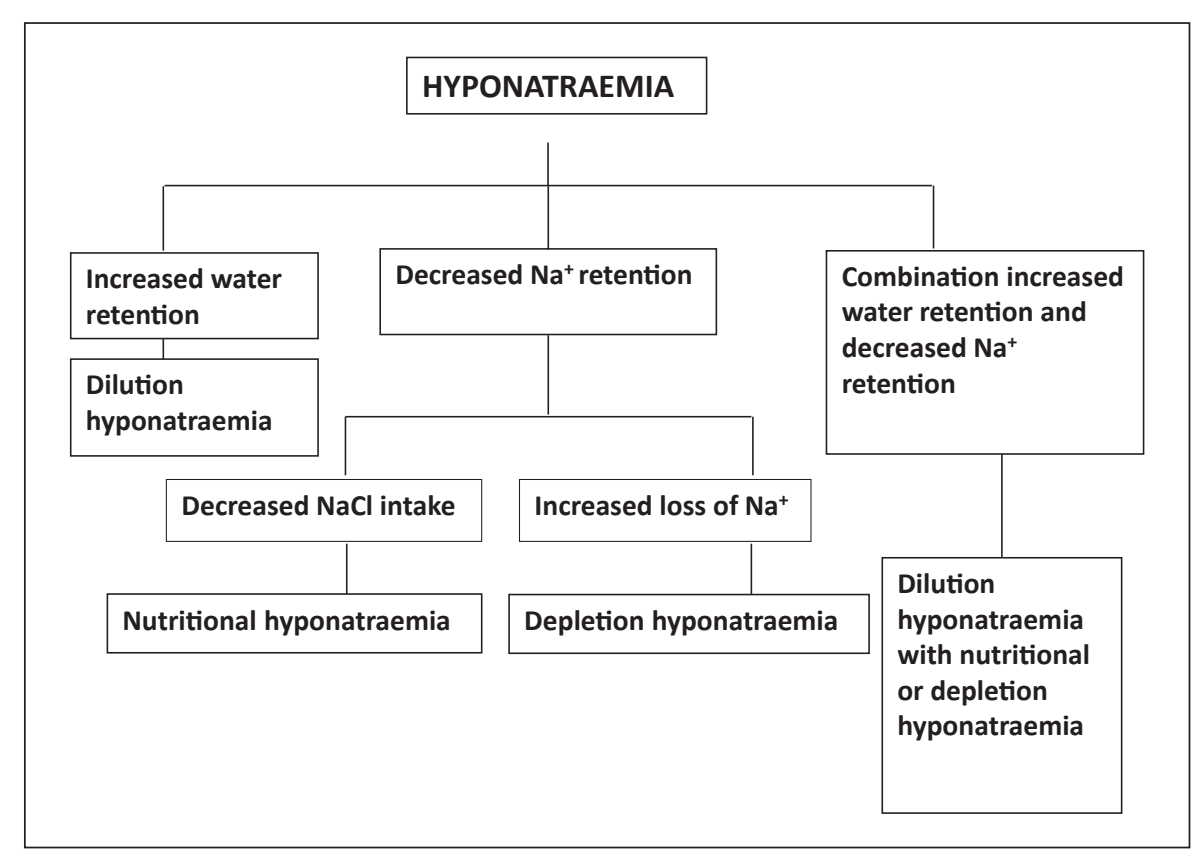

\section{Statement of Ethics}

All study participants signed an informed consent. The study protocol was approved by the Fresenius Medical Care - DS, s.r.o. ethical commission (approval reference number 166/16, 21 April 2016). The research was conducted ethically in accordance with the World Medical Association Declaration of Helsinki.

\section{Conflict of Interest Statement}

The authors have no conflicts of interest to declare.

\section{Funding Sources}

The research was not funded.

\section{Author Contributions}

M.T. designed the study; O.S. suggested the method of sodium intake estimation; L.V. processed and evaluated acquired laboratory and clinical data; M.T., O.S., L.V., and M.H. discussed findings and participated in the preparation of the article.

\section{Acknowledgements}

The authors thank the dialysis centre nurses team for taking blood samples and thank Dr. Marketa Hraskova for help with the English translation.
Novel Algorithm for Differential Diagnosis of Hyponatraemia in Anuria 


\section{References}

1 Rhee CM, Ayus JC, Kalantar-Zadeh K. Hyponatremia in the dialysis population. Kidney Int Rep. 2019 Jun;4(6):769-80.

2 Hecking M, Karaboyas A, Saran R, Sen A, Hörl WH, Pisoni RL, et al. Predialysis serum sodium level, dialysate sodium, and mortality in maintenance hemodialysis patients: the dialysis outcomes and practice patterns study (DOPPS). Am J Kidney Dis. 2012 Feb;59(2) 238-48.

3 Pérez-García R, Palomares I, Merello JI, Ramos R, Maduell F, Molina M, et al. Hyponatraemia, mortality and haemodialysis: an unexplained association. Nefrologia. 2016 Jan; 36(1):42-50.

4 Rhee CM, Ravel VA, Ayus JC, Sim JJ, Streja E, Mehrotra R, et al. Pre-dialysis serum sodium and mortality in a national incident hemodialysis cohort. Nephrol Dial Transplant. 2016 Jun;31(6):992-1001.

5 Dekker MJ, Marcelli D, Canaud B, Konings CJ, Leunissen KM, Levin NW, et al. Unraveling the relationship between mortality, hyponatremia, inflammation and malnutrition in hemodialysis patients: results from the international MONDO initiative. Eur J Clin Nutr. 2016 Jul;70(7):779-84.

6 Mc Causland FR, Waikar SS, Brunelli SM. The relevance of dietary sodium in hemodialysis. Nephrol Dial Transplant. 2013 Apr; 28(4):797-802.

7 Drozdz M, Weigert A, Silva F, Frazão J, Alsuwaida A, Krishnan M, et al. KDIGO clinical practice guideline for anemia in chronic kidney disease. Kidney Int Suppl 2012;2(4):279_ 336.

8 Kidney Disease: Improving Global Outcomes (KDIGO) CKD-MBD Work Group. KDIGO clinical practice guideline for the diagnosis, evaluation, prevention, and treatment of Chronic Kidney Disease-Mineral and Bone Disorder (CKD-MBD). Kidney Int Suppl. $2009 \operatorname{Aug}(113):$ S1-130.

9 KDIGO Blood Pressure Work Group. KDIGO clinical practice guideline for the management of blood pressure in chronic kidney disease. Kidney Int. 2012;2:337-414.

10 Tattersall J, Martin-Malo A, Pedrini L, Basci A, Canaud B, Fouque D, et al. EBPG guideline on dialysis strategies. Nephrol Dial Transplant. 2007;22(Suppl 2):ii5-21.

11 Kuhlmann U, Maierhofer A, Canaud B, Hoyer J, Gross M. Zero diffusive sodium balance in hemodialysis provided by an algorithmbased electrolyte balancing controller: a proof of principle clinical study. Artif Organs. 2019 Feb;43(2):150-8.

12 Machek P, Jirka T, Moissl U, Chamney P, Wabel P. Guided optimization of fluid status in haemodialysis patients. Nephrol Dial Transplant. 2010 Feb;25(2):538-44.

13 Mallamaci F, Benedetto FA, Tripepi R, Rastelli S, Castellino P, Tripepi G, et al. Detection of pulmonary congestion by chest ultrasound in dialysis patients. JACC Cardiovasc Imaging. 2010 Jun;3(6):586-94.
14 Zoccali C, Moissl U, Chazot C, Mallamaci F, Tripepi G, Arkossy O, et al. Chronic fluid overload and mortality in ESRD. J Am Soc Nephrol. 2017 Aug;28(8):2491-7.

15 Kamel SK, Halperin ML. Sodium and water physiology, 217. In: Kamel KS, Halperin ML, editors. Fluid, electrolyte, and acid-base physiology. 5th ed. Philadelphia: Elsevier; 2017.

16 Chiang WF, Hsiao PJ, Wu KL, Chan JS. Association of predialysis serum sodium level with fluid status in patients on maintenance hemodialysis. Int Urol Nephrol. 2020 Aug;52(8):1571-9.

17 Shah SR, Bhave G. Using electrolyte free water balance to rationalize and treat dysnatremias. Front Med. 2018 Apr 23;5:103.

18 Kawano Y, Tsuchihashi T, Matsuura H, Ando $\mathrm{K}$, Fujita T, Ueshima H. Working group for dietary salt reduction of the japanese society of hypertension. report of the working group for dietary salt reduction of the Japanese society of hypertension: (2) assessment of salt intake in the management of hypertension. Hypertens Res. 2007 Oct;30(10):887-93.

19 Patel RV, Matthie JR, Withers PO, Peterson EL, Zarowitz BJ. Estimation of total body and extracellular water using single- and multiplefrequency bioimpedance. Ann Pharmacother. 1994 May;28(5):565-9.

20 Kramer H, Yee J, Weiner DE, Bansal V, Choi $\mathrm{MJ}$, Brereton L, et al. Ultrafiltration rate thresholds in maintenance hemodialysis: an NKF-KDOQI controversies report. Am J Kidney Dis. 2016 Oct;68(4):522-32. 